\title{
Aus Rot wird Gelb
}

Die Titelseite im Wandel der Zeit

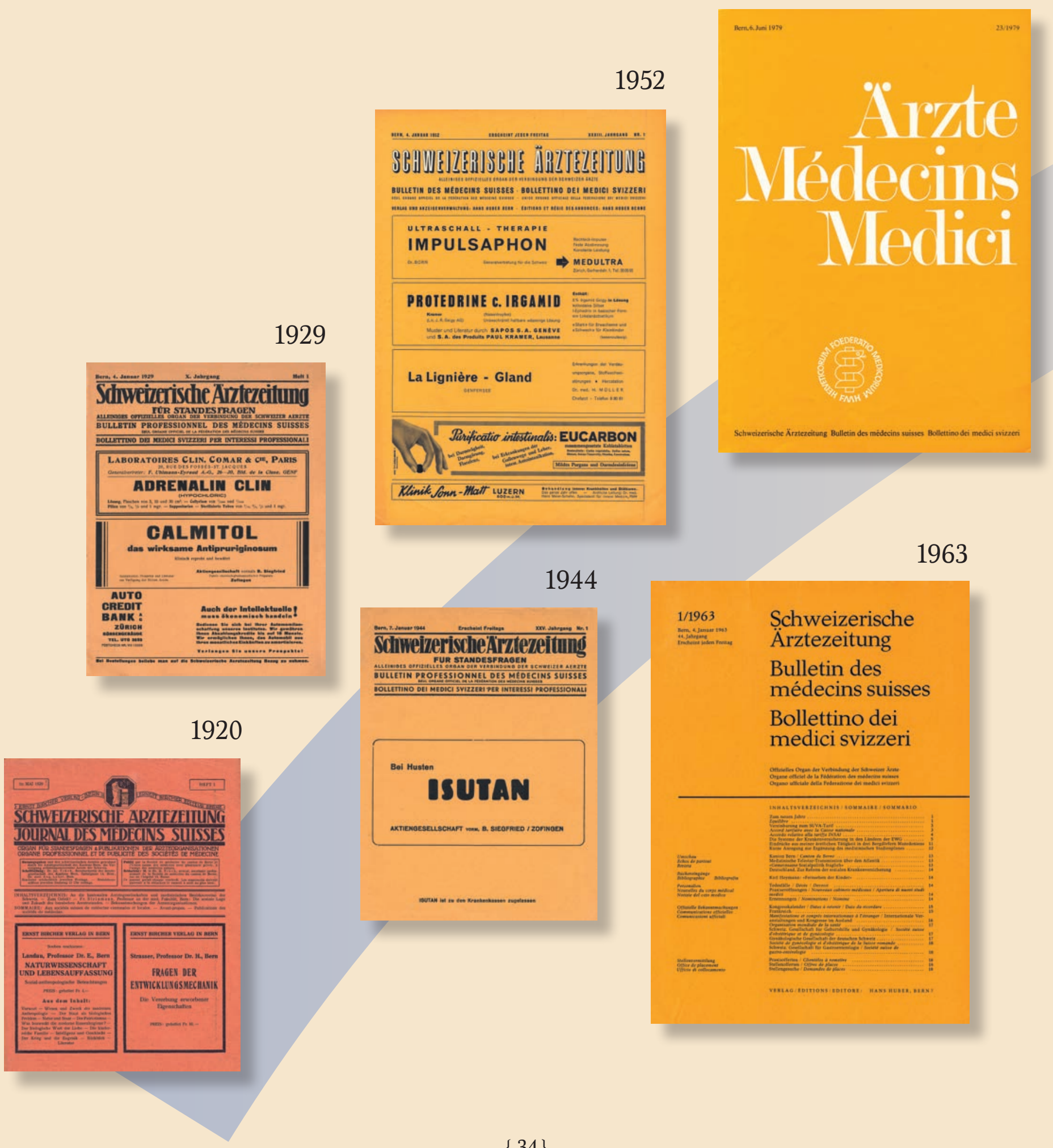


1995

\section{$\$ \mathrm{FMH}^{-=}$}

Schweizerische Ärztezeitung

Bulletin des médecins suisses

Bollettino dei medici svizzeri

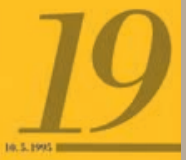

1989

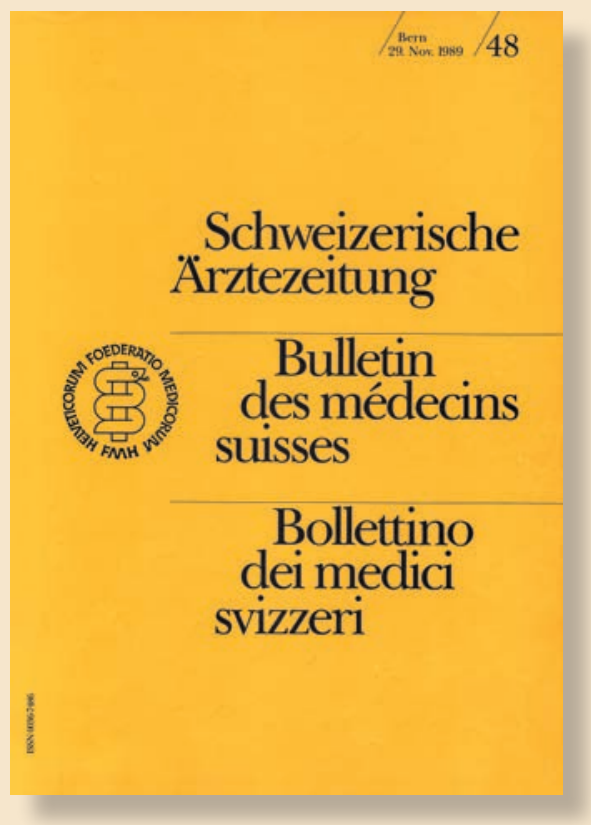

2002

15

Schweizerische Ärztezeitung Bulletin des médecins suisses Bollettino dei medici svizzeri Guideline: Oberwachung und Management bei Oberschretun des Geburtstermin

ЕМн 2 пㅜ

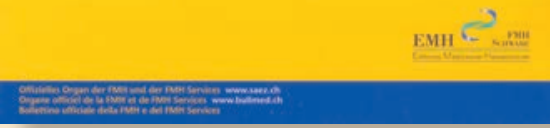

3is -

Schweizerische Ärztezeitung

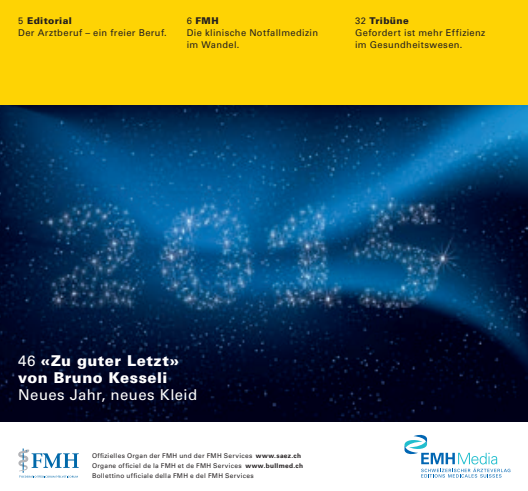

2006

1998

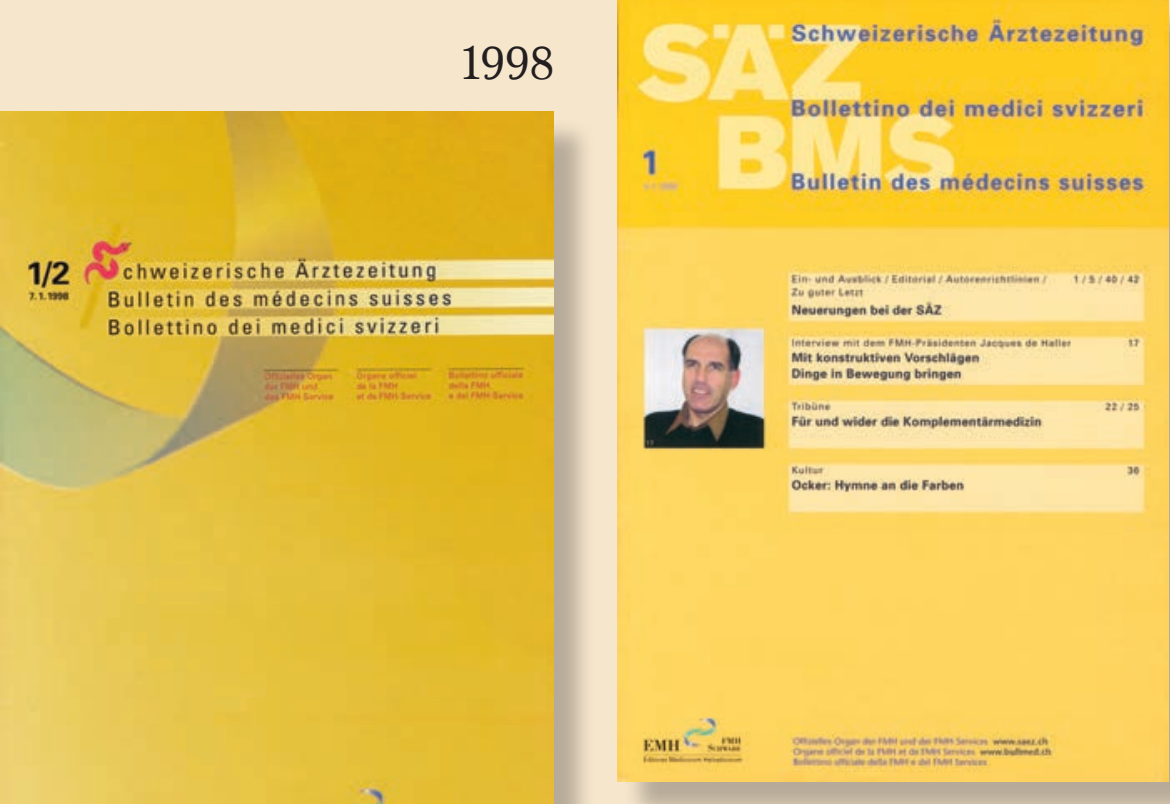

Schweizerische Ärztezeitung

dei medici svizzeri

40143

\section{0}

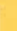

